\title{
Floppy Mitral Valve Syndrome
}

Minardi Giovanni ${ }^{1 *}$, Pulignano Giovanni², Tinti Maria Denitza ${ }^{3}$, Tolone Stefano² and Mattacola Patrizia ${ }^{2}$

${ }^{1}$ Department of Cardiovascular, Respiratory, Nephrologic and Geriatric Sciences, Sapienza University of Rome, Italy

${ }^{2}$ Department of Cardiology, Hospital San Camillo-Forlanini, Rome

${ }^{3}$ Cardiology Unit, Hospitals of Ospedali Riuniti Anzio-Nettuno, Rome

\section{Floppy Mitral Valve Syndrome}

The floppy mitral valve syndrome (FMVS) could be considered as part of a well-recognized syndrome of heritable connective tissue disorders, such as Marfan syndrome, Elher-Danlos syndrome, adult polycystic kidney disease, Ebstein's anomaly, muscular dystrophy, Grave's disease, scoliosis. Not rarely floppy mitral valve (FMV) patients present some findings of Marfan disease, like thoracic deformities, long limbs, skin abnormalities and aortic dilatation, indicating "a phenotype continuum" [1-4]. Floppy tricuspid and aortic valves have been described $[5,6]$.

From a genetic perspective, two forms of inheritance have been identified at the moment: the former is an autosomal dominant form with a variable degree of penetration (three gene loci have been identified: chromosome 16,11 and 13), the latter is transmitted through the X-chromosome [7-11]. Prevalence of FMVS in general population is $<1 \%$. FMVS patients show a particular mitral valve anatomy, characterized by diffuse or regional thickening and redundant leaflets, with altered 2:1 ratio of the anterior to posterior surface area, elongated and/or ruptured chordae tendineae, annular dilation. As a consequence of these anatomic findings some changes occur over time in the global function of mitral valve apparatus: one, both or a portion of leaflets (usually scallop P2 and segment A2) extend above the atrio-ventricular plane during systole, initially during the mid- and late- phase and, over time, during all systole. Two effects occur: the prolapsing leaflet (or its portion) occupies part of the left atrium, creating a third chamber between mitral annular plane and prolapsing leaflet, in which an amount of blood flows during systole, reducing the effective left ventricular stroke volume; the prolapsing leaflet (or its portion) and annular dilatation can modify the leaflets apposition and coaptation, creating an effective regurgitant orifice and causing mitral regurgitation of various degree; in this way the left ventricular stroke volume decreases and the left atrial pressure increases. A myxomatous degeneration with mucopolysaccaryde infiltration, elastin fragmentation, collagen disruption and dissolution in the pars fibrosa of the leaflets and in the cordae tendineae have been demonstrated by histology in patients who had reconstructive mitral valve surgery for severe regurgitation and prolapse of posterior and/or anterior leaflets [12-14].

It is necessary a long-term follow-up and several clinical and echocardiographic evaluations to understand the natural life history of FMVS. The most common symptoms are palpitations, sensation of "a thumping heart", cardiac arrhythmias, syncope, dispnea, chest pain (not related to coronary artery disease), fatigue, difficulty breathing or shortness of breath, often when lying flat or during physical activity. In many cases these symptoms precede significant mitral valve regurgitation and are more common in women than in men. These symptoms seem related to neuroendocrine or autonomic nervous system functional abnormalities and to anatomic and functional mitral valve alterations [15-17].

Other symptoms can be attributed to complications such as progressive valve regurgitation, an acute and severe valve regurgitation, congestive heart failure, infective endocarditis, cardiac arrhythmias, tromboembolic events. The sudden appearance of severe mitral regurgitation and of pulmonary oedema in patient with known mitral valve disease is usually due to the acute rupture of the cordae tendineae and related hemodynamic consequences. Physical examination revealed in many patients' skeletal abnormalities such as pectus excavatum, scoliosis, a narrow anteroposterior chest diameter, an altered body height to weight ratio compared to normal subjects. On cardiac auscultation, a mid-telesystolic click alone or combined with mid-telesystolic murmur at the apex radiating to left sternal border or to axilla and/or spine, with typical changes with posture, is generally present. Echocardiography (M-mode, 2D, Doppler, Color, $3 \mathrm{D})$ is the most widely used method for diagnosis and follow-up of FMVS, allowing the precise evaluation of mitral apparatus anatomy and function, LV and LA dimension and function, systolic pulmonary artery pressure in basal and stress condition, aortic dimension. In our experience 2D-TTE, performed by an experienced echo-lab, demonstrated a very good diagnostic accuracy in defining the anatomy and function of mitral apparatus, localizing the scallops/segments involved in degenerative mitral regurgitation, particularly for the middle ones (P2-A2), which represent almost the totality of prolapses [18]. More invasive, time consuming and expensive exams (TEE and/ or 3D-Echo, Cardiac Magnetic Resonance, cardiac catheterization) should be reserved to selected cases addressed to surgery [19] or other repair techniques such as mitra-clip [20].

International Guidelines [21-23] clearly identified all conditions in which is recommended surgical repair or replacement with prosthetic valve or in which transcatheter mitral valve repair, using mitra-clip device, is preferable because of prohibitive surgical risk.

\section{References}

1. Leier CV, Call TD, Fulkerson PK, Wooley CF (1980) The spectrum of cardiac defects in the Elhers-Danlos syndrome, Types I and III. Ann Intern Med 92: 171-178.

2. Bowen J, Boudoulas H, Wooley CF (1987) Cardiovascular disease of connective tissue origin. Am J Med 82: 481-488.

3. Glesby MJ, Pyeritz RE (1989) Association of mitral valve prolapse and systemic abnormalities of connective tissue: A phenotype continuum. JAMA 262: 523-526.

4. Hirata K, Triposkiadis F, Sparks E, Bowen J, Boudoulas H, et al. (1992) The

*Corresponding author: Minardi Giovanni, Professor in Cardiology, Department of Cardiovascular, Respiratory, Nephrologic and Geriatric Sciences, Sapienza University of Rome, Via Monte Bianco 11, 00060 Castelnuovo di Porto (RM) Italy, Tel: +393356385039; E-mail: giovanniminardi1950@gmail.com

Received July 13, 2017; Accepted July 25, 2017; Published July 28, 2017

Citation: Giovanni M, Giovanni P, Denitza TM, Stefano T, Patrizia M (2017) Floppy Mitral Valve Syndrome. J Cardiovasc Dis Diagn 5: 288. doi: 10.4172/2329. 9517.1000288

Copyright: (c) 2017 Giovanni M, et al. This is an open-access article distributed under the terms of the Creative Commons Attribution License, which permits unrestricted use, distribution, and reproduction in any medium, provided the original author and source are credited. 
Citation: Giovanni M, Giovanni P, Denitza TM, Stefano T, Patrizia M (2017) Floppy Mitral Valve Syndrome. J Cardiovasc Dis Diagn 5: 288. doi: 10.4172/2329-9517.1000288

Page 2 of 2

Marfan syndrome: Cardiovascular physical findings and diagnostic correlates. Am Heart J 123: 743-752.

5. Waller BF (1986) Etiology of pure tricuspid regurgitation. Cardiovasc Clin 17 53-95.

6. Bellitti R, Caruso A, Festa M, Mazzei V, lesu S, et al. (1985) Prolapse of the "floppy" aortic valve as a cause of aortic regurgitation. A clinico-morphologic study. Int J Cardiol 9: 399-412.

7. Devereux RB, Brown WT, Kramer-Fox R, Sachs I (1982) Inheritance of mitra valve prolapse: Effect of age and sex on gene expression. Ann Intern Med 97 826-832.

8. Bastug S, San C, Aslan AN, Bayram NA, Ayhan H, et al. (2015) Evaluation of autoimmune thyroid disease in patients with mitral valve prolapse. Erciyes Med J 37: 98-101.

9. Grau JB, Pirelli L, Yu PJ, Galloway AC, Ostrer H (2007) The genetics of mitra valve prolapse. Clin Genet 72: 288-295.

10. Boudoulas KD, Boudoulas $H$ (2013) Floppy mitral valve (FMV) mitral valve prolapse (MVP) and FMV/MVP syndrome: Pathophysiologic mechanism and pathogenesis of symptoms. Cardiology 126: 69-80.

11. Boudoulas KD, Pitsis AA, Boudoulas $H$ (2016) Floppy mitral valve (FMV)-Mitra valve prolapse (MVP)-Mitral valvular regurgitation and FMV/MVP syndrome. Hellenic J Cardiol 7: 73-85.

12. Wooley CF, Baker PB, Kolibash AJ, Kilman JW, Sparks EA, et al. (1991) The floppy, myxomatous mitral valve and mitral regurgitation. Prog Cardiovasc Dis 33: $397-433$

13. Roberts WC, Vowels TJ, Ko JM, Hebeler RF (2014) Gross and histological features of excised portions of posterior mitral leaflet in patients having operative repair of mitral valve prolapse and comments on concept of missing (rupture) chordae tendineae. J Am Coll Cardiol 63: 1667-1674.
14. Boudoulas H, Kolibash AJ, Baker P, King BD, Wooley CF (1989) Mitral valve prolapse and the mitral valve prolapse syndrome: a diagnostic classification and pathogenesis of symptoms. Am Heart J 118: 796-818.

15. Boudoulas H, Schaal SF, Wooley CF (1998) Floppy mitral valve/mitral valve prolapse: Cardiac arrhythmias; in Vardas PE (ed): Cardiac arrhythmias, pacing and electrophysiology. Dordrecht, Kluwer Academics, The Netherlands p. 89-95.

16. Sanfilippo AJ, Harrigan P, Popovic AD, Weyman AE, Levine RA (1992) Papillary muscle tension in mitral valve prolapse Quantitation by two-dimensional echocardiography. J Am Coll Cardiol 19: 564-571.

17. Franz MR, Cima R, Wang D, ProfittD, Kurz R (1992) Electrophysiological effects of myocardial stretch and mechanical determinants of stretch-activated arrhythmias. Circulation 86: 968-978.

18. Minardi G, Pino PP, Manzara CC, Pulignano G, Stefanini G, et al. (2010) Preoperative scallop-by-scallop assessment of mitral prolapse using 2D-transthoracic echocardiography. Cardiovasc Ultrasound 8.

19. Fedak PWM, McCarthy PM, Bonow RO (2008) Evolving concepts and technologies in mitral valve repair. Circulation 117: 963-974.

20. Kelley C, Lazkani M, Farah J, Pershad A (2016) Percutaneous mitral valve repair: a new treatment for mitral regurgitation. Indian Heart Journal 68: 399-404.

21. AHA/ACC (2012) Guidelines on the management of valvular heart disease Eur Heart J 33: 2451-2496.

22. Nishimura RA (2014) AHA/ACC Guideline for the management of patients with valvular heart disease: Executive Summary. Circulation.

23. Nishimura RA (2017) AHA/ACC Focused Update of the 2014 AHA/ACC Guideline for the management of patients with valvular heart disease a report of the American College of Cardiology/American Heart Association: Task Force on Clinical Practice Guidelines VHD. Circulation. 